\title{
EL ESCLARECIMIENTO DE LA VERDAD, LA CONFESIÓN Y EL DERECHO DE NO AUTOINCRIMINACIÓN Y DE GUARDAR SILENCIO EN LOS CONTEXTOS JUDICIALES DE TRANSICIÓN. EL CASO DE JUSTICIA Y PAZ EN COLOMBIA
}

\section{Heydi Patricia Baldosea Perea*}

\begin{abstract}
Resumen: Los escenarios de justicia transicional reseñan el componente de la verdad y el reconocimiento de las responsabilidades personales como fundamentales, dados los derechos de las víctimas a la verdad, la justicia, la reparación y la garantía de no repetición; así, en el proceso transicional de Justicia y Paz, la verdad es un presupuesto u obligación para quienes se acojan a ese mecanismo transicional con la aspiración de obtener los beneficios
\end{abstract}

Abogada especializada en Instituciones Jurídico Procesales en la Universidad Nacional de Colombia, en Derechos Humanos en la Universidad Complutense de Madrid con reconocimiento por máximas calificaciones y Mención de Honor; y en Investigación Criminal y Juzgamiento en el Sistema Penal Acusatorio en la Universidad Católica. Asistente de investigación en publicaciones de Derechos Humanos. Funcionaria pública en la Rama judicial, abogada litigante, consultora y asistente de investigación. Actualmente ejerce como Defensora Pública en el programa de Justicia y Paz. Bogotá, Colombia. Correo-e: heydi.baldosea@gmail.com. Fecha de recepción: 24 de abril de 2017. Fecha de modificación: 26 de mayo de 2017. Fecha de aceptación: 31 de agosto de 2017. Para citar el artículo: HeYdi PATRICIA BALdosea PEREA. "El esclarecimiento de la verdad, la confesión y el derecho de no autoincriminación y de guardar silencio en el contextos judiciales de transición. El caso de justicia y paz en colombia" en Revista Derecho Penal y Criminología, Vol. 38, n. ${ }^{\circ}$ 104, enero-junio de 2017, Bogotá, Universidad Externado de Colombia, pp. 151-177. DOI: https://doi.org/10.18601/ 01210483.v38n104.05 
previstos por esta legislación al desmovilizado, al punto que se ha configurado una etapa procesal de carácter judicial en la cual el desmovilizado-postulado, renunciando a su derecho constitucional de no autoincriminación y de guardar silencio, confiesa todos y cada uno de los casos delictuales en los que tuvo participación o con conocimiento durante y con ocasión de su pertenencia al grupo armado organizado al margen de la ley, con lo cual se evidencia la tensión entre los derechos del acusado -incluso el referido al de no ser usado como medio de prueba en su contra, es decir, la garantía que lo protege de ser obligado a incriminarse-, y el derecho de las víctimas y la sociedad a saber lo ocurrido y conocer la verdad.

Palabras clave: Justicia transicional, No autoincriminación, Confesión, Verdad, Justicia y Paz.

\title{
THE CLARIFICATION OF THE TRUTH, THE CONFESSION AND THE RIGHT NOT TO SELF-INCRIMINATION AND TO REMAIN SILENT IN THE JUDICIAL CONTEXTS OF TRANSITION. THE CASE OF JUSTICE AND PEACE IN COLOMBIA
}

\begin{abstract}
In transitional justice scenarios, truth and the recognition of personal responsibilities are fundamental components; In the transitional process of Justice and Peace, the truth is a budget and obligation for those who take advantage of this transitional mechanism with the aspiration to obtain the benefits provided by this legislation to the demobilized; that a judicial procedural stage has been set up In which the demobilized-postulate, renouncing his constitutional right not to self-incriminate and to remain silent, confesses each and every one of the criminal cases in which he participated or with knowledge during and on the occasion of his membership in the illegal group. Which shows the tension between the defendant's rights - including that of not being used as a means of evidence against him, that is, the guarantee that protects him from being forced to incriminate himself - and the right of the victims and Society to know what happened and know the truth.
\end{abstract}

Keywords: Transitional justice, Not self-incrimination, Confession, Truth, Justice and Peace.

\section{INTRODUCCIÓN}

La aplicación de la justicia durante contextos de transición incorpora un enfoque restaurativo en el establecimiento y reconocimiento de las responsabilidades personales, así como en la determinación y esclarecimiento de lo ocurrido en el conflicto armado; por ello, los consensos nacionales e internacionales en torno a los requerimientos básicos de la justicia de transición -de promoción y edificación de los derechos a 
la Verdad, la Justicia y la Reparación-, reseñan el componente de la verdad como fundamental en este contexto judicial, ya no como el mecanismo de solución por medio del aporte y controversia probatoria de las diferencias de dos contendores en el proceso penal (acusación y defensa), sino en donde la administración de justicia, en pro de la convivencia pacífica, la reconciliación y la reintegración a la vida civil, asumen un papel dinámico de constructor de memoria colectiva a través del estudio judicial de las condiciones históricas del conflicto armado y sus actores, a partir del deber jurídico del Estado de proteger los derechos humanos y de una efectiva tutela judicial para "dejar constancia de los hechos históricos con un sello jurídico"'.

La dimensión de la verdad en este contexto se edifica no solo a partir del derecho individual y colectivo que le corresponde a la víctima y a la sociedad sino también a través de la obligación del Estado para que el conocimiento de lo que ocurrió sea garantizado de forma concreta y efectiva; así, en el proceso transicional de Justicia y Paz, la verdad es un presupuesto u obligación para quienes se acojan a ese mecanismo transicional con la aspiración de obtener los beneficios previstos por esta legislación al desmovilizado, al punto que aquella se ha configurado normativamente como causal de pérdida del beneficio de alternatividad ${ }^{2}$ si se desconoce o fragmenta. Para ello, paralelo al reconocimiento del "derecho a saber", esta normatividad configuró un "deber de verdad" como un compromiso del desmovilizado que accede al procedimiento, el cual debe concretarse al rendir una confesión "completa, verídica y detallada".

En efecto, el proceso de justicia y paz prevé la construcción de la verdad desde la instancia pre-procesal inicial de la versión libre, vale decir, una diligencia de carácter judicial en la cual el desmovilizado-postulado, renunciando a su derecho constitucional de no autoincriminación y de guardar silencio, confiesa todos y cada uno de los casos delictuales en los que tuvo participación o con conocimiento durante y con ocasión de su pertenencia al grupo armado organizado al margen de la ley; desde este escenario, comienza, entonces, la construcción de verdad a partir de conciliar la verdad expuesta y aportada por el procesado, con el conocimiento particular de las víctimas y de la sociedad en general representada a través de instituciones como el Ministerio Público, que están legitimadas para intervenir, controvertir y discutir el contenido de la versión del procesado.

1 Yasmin NAQvi. "El derecho a la Verdad en el Derecho Internacional: ¿realidad o ficción?”, en International Review of the Red Cross, junio de 2006, n. ${ }^{\circ} 862$ de la versión original. http://www.icrc. org/spa/assets/files/other/irrc_862_naqvi.pdf.

2 Artículo 3 de la Ley 975 de 2005. "Alternatividad es un beneficio consistente en suspender la ejecución de la pena determinada en la respectiva sentencia, reemplazándola por una pena alternativa que se concede por la contribución del beneficiario a la consecución de la paz nacional, la colaboración con la justicia, la reparación a las víctimas y su adecuada resocialización”. 
En consecuencia, el deber de esclarecimiento de la verdad toca así con el derecho a la justicia ${ }^{3}$, también componente principal de la justicia transicional, en tanto que la verificación de aquello que ocurrió en la confrontación de la guerra generador de daños de considerable magnitud a las víctimas y la sociedad, corresponde también a la atribución de responsabilidad jurídica a aquellos que intervinieron en dichos hechos delictuales y reconocen su pertenencia a una organización armada organizada al margen de la ley o su participación directa o indirecta en la dinámica del conflicto; por ello, tal esclarecimiento tiene, además de construcción de memoria y verdad, componentes de delación y autoincriminación que toca con la figura de la "declaración del imputado" que cuenta con una especial relevancia por las garantías que ello comporta.

A lo largo de este escrito, se tratará de evidenciar la tensión que comporta la justicia transicional entre los derechos del acusado -incluso el referido al de no ser usado como medio de prueba en su contra, es decir, la garantía que lo protege de ser obligado a incriminarse - , y el derecho de las víctimas y la sociedad a saber lo ocurrido y conocer la verdad.

\section{EL DERECHO A LA VERDAD Y LA JUSTICIA TRANSICIONAL}

Específicamente, existe una estrecha relación entre la justicia de transición, verdad e historia, pues en "el discurso de la justicia transicional, volver a visitar el pasado es entendido como el modo de avanzar hacia el futuro (...) las transiciones son períodos atípicos de quiebre que ofrecen una elección entre narrativas en disputa. El objetivo paradójico de la transición es deshacer la historia. La finalidad es reconcebir el significado social de conflictos pasados, en particular de las derrotas, en un intento por reconstruir sus efectos presentes y futuros..."4.

Al respecto, se cuenta con los conceptos de la Secretaría General de las Naciones Unidas que reconoce este derecho como prerrogativa de las víctimas y obligación en

3 Naciones Unidas, “Conjunto de Principios para la protección y la promoción de los derechos humanos mediante la lucha contra la impunidad", proclamados por la Comisión de Derechos Humanos ONU en 1998. Joinet, L. ONU, Comisión de Derechos Humanos, $49^{\circ}$ período de sesiones: "B. El derecho a la justicia. 1. El derecho a un recurso justo y eficaz. 27. El derecho a la justicia confiere al Estado una serie de obligaciones: la de investigar las violaciones, perseguir a sus autores y, si su culpabilidad es establecida, de asegurar su sanción. Si la iniciativa de investigar corresponde en primer lugar al Estado, las reglas complementarias de procedimiento deben prever que todas las víctimas puedan ser parte civil y, en caso de carencia de poderes públicos, tomar ella misma la iniciativa". Informe final revisado acerca de la cuestión de la impunidad de los autores de violaciones de los derechos humanos (derechos civiles y políticos) preparado por el Sr. L. Joinet de conformidad con la resolución 1996/119 de la Subcomisión, Doc. E/CN.4/Sub.2/1997/20/Rev.1, anexo II.

4 Teitel Ruti G. “Transitional Justice Genealogy”, en Harvard Human Rights Journal, Vol. 16, Cambridge, MA, Spring 2003, pp. 69-94. 
el marco de la justicia de transición ${ }^{5}$; efectivamente, en el informe que el Secretario General presentó ante el Consejo de Seguridad sobre el Estado de Derecho y la Justicia de transición en el año 2004[6], se advierte de la importancia de la constatación de los hechos pasados que están relacionados con las infracciones de los derechos humanos y el DIH como mecanismo indispensable en los procesos de transición; todo ello unido a las recomendaciones que tanto la Asamblea como el Consejo de Seguridad han suscitado respecto a la promoción de Comisiones de la Verdad en los casos de delitos de Lesa humanidad, Genocidio, delitos de Guerra y violaciones de derechos humanos.

Asimismo, a lo largo de su construcción, el contexto de transición ha tocado la sensibilidad de la comunidad internacional acerca de la necesidad de que se garantice el cumplimiento de los derechos de las víctimas, cuyo avance se debe en gran medida en la consolidación del informe presentado por la experta a Louis Joinet a quien en el año 1991 la entonces Subcomisión de prevención de discriminaciones y protección de las minorías de la Comisión de Derechos Humanos de Naciones Unidas le había encargado realizar un estudio sobre la cuestión de la impunidad de los autores de violaciones de los derechos humanos; en el informe presentado a la Comisión se indica que a las víctimas les asisten los siguientes derechos: a) El derecho a saber de la víctima; b) El derecho de la víctima a la justicia, y c) El derecho a la reparación de la víctima; a los cuales se le se suman medidas destinadas a garantizar la no reiteración de las violaciones ${ }^{7}$.

En cuanto al derecho "a saber" o a la verdad, se precisa que no se trata solamente del derecho individual que toda víctima o sus parientes sino que también de un derecho colectivo que tiene su razón de ser en la necesidad de prevenir que las violaciones se repitan. Además, se complementa el contenido del mismo a través de unos principios básicos ${ }^{8}$ que lo conforman y que corresponde a i) Principio 1. Derecho

5 Naciones Unidas, "The rule of law and transitional justice in conflict and post-conflict societies", $\mathrm{S} / 2004 / 16$

6 Naciones Unidas, Informe del Secretario General sobre el Estado de Derecho y la justicia de transición en las sociedades que sufren o han sufrido conflictos. S/2004/616. Parr 50

7 Ob. cit. Conjunto de principios para la protección y la promoción de los derechos humanos para la lucha contra la impunidad de Joinet.

8 El informe también incorpora otros conceptos como los de comisiones de la verdad, "órganos oficiales, temporales y de constatación de hechos que no tienen carácter judicial y se ocupan de investigar abusos de los derechos humanos o el derecho humanitario que se hayan cometido a lo largo de varios años", y archivos: "colecciones de documentos relativos a violaciones de los derechos humanos y el derecho humanitario de fuentes que incluyen: a) organismos gubernamentales nacionales, en particular los que hayan desempeñado una función importante en relación con las violaciones de los derechos humanos; b) organismos locales, tales como comisarías de policía, que hayan participado en violaciones de los derechos humanos; c) organismos estatales, incluida la oficina del fiscal y el poder judicial, que participan en la protección de los derechos humanos; y d) materiales reunidos por las comisiones de la verdad y otros órganos de investigación". 
inalienable a la verdad: "Toda sociedad tiene el derecho inalienable a conocer la verdad acerca de los acontecimientos sucedidos y las circunstancias y los motivos que llevaron, mediante la violación masiva y sistemática de los derechos humanos, a la perpetración de crímenes aberrantes. El ejercicio pleno y efectivo del derecho a la verdad es esencial para evitar que en el futuro se repitan tales actos. ii) Principio 2. El deber de recordar: "El conocimiento por un pueblo de la historia de su opresión forma parte de su patrimonio y, por ello, se debe conservar adoptando medidas adecuadas en aras del deber de recordar que incumbe al Estado. Esas medidas tienen por objeto preservar del olvido la memoria colectiva, entre otras cosas para evitar que surjan tesis revisionistas y negacionistas"; iii) Principio 3. El derecho de las víctimas a saber "Independientemente de las acciones que puedan entablar ante la justicia, las familias de las víctimas tienen derecho a conocer la suerte que corrieron sus parientes. En caso de desaparición forzosa o de secuestro de menores, este derecho es imprescriptible"; y iv) Principio 4. Garantías para hacer efectivo el derecho a saber. "Para hacer efectivo el derecho a saber, los Estados deberían adoptar las medidas siguientes a fin de crear comisiones extrajudiciales de investigación y para asegurar la conservación de los archivos del período de referencia y su consulta". Estos principios fueron actualizados y adicionados en el año 2005 por medio del Informe de la experta independiente Diane Orentlicher (E/CN.4/2005/102/Add.1 8 de febrero de 2005)

El proceso normativo de este derecho dentro del sistema jurídico internacional ha sido paralelo al desarrollo de otros temas de los derechos humanos, en los que es constante la reivindicación del derecho que tienen familiares y víctimas a saber lo ocurrido. Así, por ejemplo, las primeras previsiones de esta prerrogativa se fundaron en los contenidos de las normas del Derecho Internacional Humanitario que consagraban el derecho de los familiares de las víctimas a conocer el paradero de los combatientes desaparecidos en combate o en poder de las fuerzas enemigas, ello consagrado en textos como las Conferencias internacionales de París (1867) y Berlín (1869) ${ }^{9}$, y de manera en especial en el artículo 32 del Protocolo Adicional I a los Convenios de Ginebra del 12 de agosto de 1949 relativo a la Protección de las Víctimas de los Conflictos Armados Internacionales, que reconoce el derecho que asiste a las familias de conocer la suerte de sus miembros (art. 32), y el artículo 33 del mismo que dispone la obligación de las partes en conflicto de buscar a las personas desaparecidas tan pronto como las circunstancias lo permitan; al respecto, el Comité Internacional de la Cruz Roja (CICR) concluyó que este derecho es una norma

9 Bugnion, FrançoIs. Le Comité international de la Croix-Rouge et la protection des victimes de la guerre, Ed. Comité International de la Croix-Rouge, Ginebra, 1994, pp. 569 y ss., citado por FEDERICo ANDREU-GuZMÁn, Subdirector de Litigio y Protección Jurídica de la Comisión Colombiana de Juristas. Comisión Colombiana de Juristas, Derecho a la Verdad y Derecho Internacional, Bogotá, primera edición 2012. Disponible en línea en http://www.coljuristas.org/documentos/libros_e_informes/derecho_a_la_verdad_y_derecho_internacional.pdf. 
del derecho internacional consuetudinario, con aplicación a los conflictos armados tanto de carácter internacional como interno ${ }^{10}$.

Otro punto de partida para abordar el tema del derecho a la verdad lo constituyen principalmente los aportes del Sistema Interamericano de Derechos Humanos en la materia, en tanto que a través de sus órganos -Comisión y la Corte Interamericana de Derechos Humanos- se ha hecho un avance esencial al afirmar y reiterar la existencia de un principio fundamental que sostiene la obligación del Estado de investigar las violaciones masivas y sistemáticas de derechos humanos con el propósito de revelar la verdad sobre los hechos y circunstancias en las cuales se cometieron. En el avance de la interpretación del derecho a la verdad en este escenario de Derechos Internacional de los Derechos Humanos, se tiene que tal prerrogativa está fundamentada tanto en el artículo 25 (Protección Judicial), como en los artículos 1(1) (Obligación de Respetar los Derechos), 8 (Garantías Judiciales) y 13 (Libertad de Pensamiento y de Expresión) de la Convención Interamericana de Derechos Humanos.

Como referencias del marco del derecho a la verdad se tienen los informes que la Comisión realizó respecto de las leyes de amnistías que fueron promulgadas por el gobierno de Chile respecto de los crímenes cometidos por la dictadura de Pinochet durante los años 1973 y 1978; en el informe, durante el acápite expresamente dedicado al "Derecho a la Verdad" se reafirma el contenido de este como una correlativa obligación del Estado dispuesta por la Convención que subsiste, por lo menos en lo que toca con la desaparición forzada, mientras se mantenga la incertidumbre de la suerte final de la persona desaparecida; además, en dicho informe se reconoce su dimensión tanto individual como colectiva:

88. El derecho a la verdad constituye un derecho de carácter colectivo que permite a la sociedad tener acceso a información esencial para el desarrollo de los sistemas democráticos y, un derecho particular para los familiares de las víctimas, que permite una forma de reparación, en particular, en los casos de aplicación de leyes de amnistía... 92. Igualmente, la Comisión ha sostenido que "Toda la sociedad tiene el irrenunciable derecho de conocer la verdad de lo ocurrido, así como las razones y circunstancias en las que aberrantes delitos llegaron a cometerse, a fin de evitar que esos hechos vuelvan a ocurrir en el futuro. A la vez, nada puede impedir a los familiares de las víctimas conocer lo que aconteció con sus seres más cercanos. Tal acceso a la verdad, supone no coartar la libertad de expresión; la formación de comisiones investigadoras cuya integración y competencia habrán de ser determinadas conforme al correspondiente derecho interno de cada país y el otorgamiento de los medios necesarios

10 Norma n. $^{\circ} 117$ en JeAn-Marie Henckaerts y Louise Doswald-Beck. El derecho internacional humanitario consuetudinario, Volumen I, Normas, Ediciones Comité Internacional de la Cruz Roja, p. 477. 
para que sea el propio Poder Judicial el que pueda emprender las investigaciones que sean necesarias"[46]... Además de los familiares de las víctimas directamente afectados por una violación a los derechos humanos, es también titular del derecho a ser debidamente informada la sociedad en general [49] ${ }^{11}$.

De manera específica, el derecho a la verdad ha sido abordado por la Corte desde la selección y configuración del contenido de la premisa normativa aplicable para los casos concretos, en la representación de la proposición jurídica "Garantía Judicial" y "Protección Judicial" previstas en normas de la Convención Americana de los Derechos Humanos (art. 8 y 25). En este sentido, por ejemplo, en la sentencia del 25 de noviembre del 2000 en el caso Bácama Velásquez vs Guatemala, el tratamiento de este punto a solicitud prevista en las alegaciones de la Comisión acerca de un pronunciamiento expreso respecto de esta prerrogativa, la Corte se circunscribe a la violación de las mencionadas garantías en los siguientes términos: "el derecho a la verdad se encuentra subsumido en el derecho de la víctima o sus familiares a obtener de los órganos competentes del Estado el esclarecimiento de los hechos violatorios y las responsabilidades correspondientes, a través de la investigación y el juzgamiento que previenen los artículos 8 y 25 de la Convención" "12; en igual sentido lo establecido en la sentencia del caso de Barrios Altos vs Perú ${ }^{13}$ y de La Rochela vs Colombia ${ }^{14}$.

Además, la Corte, en la Sentencia de reparaciones del Caso Bámaca Velásquez vs Guatemala del 22 de noviembre de $2000^{[15]}$, ha vinculado el derecho a la verdad con la reparación a favor de las víctimas: "76. El derecho que toda persona tiene a la verdad, ha sido desarrollado por el Derecho Internacional de los Derechos Humanos ${ }^{16}$, y,

11 Comisión Interamericana de Derechos Humanos. Informe n..$^{\circ}$ 25/98 Casos 11.505, 11.532, 11.541, $11.546,11.549,11.569,11.572,11.573,11.583,11.585,11.595,11.652,11.657,11.675$ у 11.705. Chile. 7 de abril de 1998. Recuperado en línea el 12 de enero de 2016, en http://cidh.oas.org/ annualrep/97span/Chile11.505.htm.

12 Corte Interamericana de Derechos Humanos. Caso Bámaca Velásquez vs Guatemala. Fondo. Sentencia de 25 de noviembre de 2000 . Serie $\mathrm{C} \mathrm{n} .^{\circ} 70$.

13 Corte Interamericana de Derechos Humanos. Caso Barrios Altos vs Perú. Fondo. Sentencia de 14 de marzo de 2001. Serie C n. ${ }^{\circ} 75$.

14 Corte Interamericana de Derechos Humanos. Caso de la Masacre de La Rochela vs Colombia. Fondo, Reparaciones y Costas. Sentencia de 11 de de mayo de 2007 . Serie C n. ${ }^{\circ} 163$.

15 Caso Bámaca Velásquez vs Guatemala. Los hechos que dieron lugar a este proceso consistieron en el apresamiento del líder guerrillero Efraín Bámaca por el ejército guatemalteco. Estando detenido fue torturado a fin de que revelara información. Y luego fue desaparecido, sin que hasta el momento de la sentencia se tuviera información sobre su paradero.

16 Véase, por ejemplo, United Nations Human Rights Committee, Quinteros v. Uruguay, Communication No. 107/1981, decision of 21 July 1983; Naciones Unidas, Comisión de Derechos Humanos, Subcomisión de Prevención de Discriminaciones y Protección a las Minorías, $49^{\circ}$ período de sesiones, Informe final revisado acerca de la cuestión de la impunidad de los autores de violaciones de los derechos humanos (derechos civiles y políticos) preparado por L. Joinet, UN General Assembly Doc. E/CN.4/Sub.2/1997/20/Rev.1; Naciones Unidas, Comisión de Derechos Humanos, Subcomisión de Prevención de Discriminaciones y Protección a las Minorías, $45^{\circ}$ período de sesiones, Estudio relativo 
como sostuvo esta Corte en anteriores oportunidades, la posibilidad de los familiares de la víctima de conocer lo sucedido a esta ${ }^{17}$, y, en su caso, dónde se encuentran sus restos $^{18}$, constituye un medio de reparación y, por tanto, una expectativa que el Estado debe satisfacer a los familiares de la víctima y a la sociedad como un todo" ${ }^{19}$.

Por su parte, en el Sistema Universal de protección de Derechos Humanos, la Asamblea General de las Naciones Unidas desde los años setenta ha promovido la discusión de este derecho desde una perspectiva anexa a los casos de desaparición forzada, en tanto que se ha referido al "deseo de saber" o a la angustia de las víctimas de desaparecidos ante la incertidumbre de su paradero ${ }^{20}$; en este sentido, el Grupo de Trabajo sobre las Desapariciones Forzadas o Involuntarias desde el inicio de su mandato y en los primeros informes dirigidos a la Comisión de Derechos Humanos de Naciones Unidas ha sido reiterativo en cuanto al derecho a la verdad que les asiste a los familiares de víctimas de desaparición forzada: "unquestionably, their right to know can be neither denied nor ignored"21. Este argumento se tradujo muchos años después en una disposición expresa en la Convención Internacional para la protección de todas las personas contra las desapariciones forzadas (Resolución 61/177, de 20 de diciembre de 2006), tanto en el preámbulo, "Afirmando el derecho a conocer la verdad sobre las circunstancias de una desaparición forzada y la suerte de la persona desaparecida, así como el respeto del derecho a la libertad de buscar, recibir y difundir informaciones a este fin", como en el artículo 24 que dispuso: "2. Cada víctima tiene

al derecho de restitución, indemnización y rehabilitación a las víctimas de violaciones flagrantes de los derechos humanos y las libertades fundamentales, Informe definitivo presentado por Theo van Boven, Relator especial, E/CN.4/Sub .2/1993/8.

17 Cfr. Caso Cantoral Benavides, Reparaciones, supra nota 5, párr. 69; Caso Villagrán Morales y otros, Reparaciones, supra nota 5, párr. 100; y Caso Paniagua Morales y otros, Reparaciones, supra nota 5, párr. 200.

18 Cfr. Caso Castillo Páez, Sentencia de 3 de noviembre de 1997. Serie C No. 34, párr. 90; Caso Caballero Delgado y Santana. Reparaciones (art. 63.1 Convención Americana sobre Derechos Humanos). Sentencia de 29 de enero de 1997. Serie C No. 31, párr. 58; y Caso Neira Alegría y Otros, Reparaciones, supra nota 38, párr. 69.

19 Cfr. Caso Castillo Páez, supra nota 6, párr. 90. En igual sentido cfr. Naciones Unidas, Comisión de Derechos Humanos, Subcomisión de Prevención de Discriminaciones y Protección a las Minorías, $49^{\circ}$ período de sesiones, Informe final revisado acerca de la cuestión de la impunidad de los autores de violaciones de los derechos humanos (derechos civiles y políticos) preparado por L. Joinet, UN General Assembly Doc. E/CN.4/Sub.2/1997/20/Rev.1; y Naciones Unidas, Comisión de Derechos Humanos, Subcomisión de Prevención de Discriminaciones y Protección a las Minorías, $45^{\circ}$ período de sesiones, Estudio relativo al derecho de restitución, indemnización y rehabilitación a las víctimas de violaciones flagrantes de los derechos humanos y las libertades fundamentales, Informe definitivo presentado por Theo van Boven, Relator especial, E/CN.4/Sub .2/1993/8.

20 Naciones Unidas, General Assembly resolutions 3220 (XXIX), 33/173, 45/165, and 47/132. ICRC commentary on article 32 of Protocol I of the Geneva Conventions, of 12 August 1949, para. 1211. Resolution II of the XXIV International Conference of the Red Cross and Red Crescent. Citados en E/CN.4/2006/91 del 9 de enero de 2006.

21 Naciones Unidas, E/CN.4/1492, de fecha 31 de diciembre de 1981, párr. 5. 
el derecho de conocer la verdad sobre las circunstancias de la desaparición forzada, la evolución y resultados de la investigación y la suerte de la persona desaparecida. Cada Estado Parte tomará las medidas adecuadas a este respecto”.

Aunque la evolución internacional del derecho a la verdad estuvo circunscrita a la existencia y violación de otros derechos humanos de alta connotación, especialmente, a través de la lucha contra la práctica de las desapariciones forzadas: "Al igual que las garantías procesales, el derecho a la verdad surge después de cometerse la violación de otro derecho humano, y aparentemente, es violado cuando las autoridades no proporcionan información particular sobre la violación inicial, sea mediante la revelación oficial de información o la aparición de esa información a raíz de un juicio, sea a través de otros mecanismos cuyo objetivo es esclarecer la verdad" 22 ; con posterioridad se caracteriza este derecho como autónomo -aunque estrechamente vinculado con otros derechos ${ }^{23}-$, con aspectos individuales y colectivos, que no admite suspensión ni restricciones, así como "inalienable, vinculado a la obligación y el deber del Estado de proteger y garantizar los derechos humanos, realizar investigaciones eficaces y velar por que haya recursos efectivos y se obtenga reparación"24. La naturaleza del derecho a la verdad, entonces, se vincula con el deber en cabeza del Estado de realizar investigaciones efectivas respecto de las graves violaciones de los derechos humanos, así como de ofrecer recursos judiciales efectivos a las víctimas con este propósito.

Así, por ejemplo, en el marco jurídico internacional del Sistema de Naciones Unidas, en la Resolución E-CN_4.Res.2005-66 como pronunciamiento del Consejo de Derechos Humanos, al tiempo que reconoce la importancia de garantizar y respetar esta potestad como medio para la eliminación de la impunidad, por un lado, avala, felicita y alienta la existencia de iniciativas estatales tendientes a incorporar mecanismos judiciales y extrajudiciales para este fin; y por otro, señala la relevancia que en los procedimientos especiales (mecanismos, relatorías e informes temáticos) se proceda a

22 Yasmin, MaQvi. Ob. cit.

23 La dignidad inherente del ser humano y el derecho a un recurso efectivo, a la protección jurídica y judicial, a la vida familiar, a una investigación eficaz, a ser oído por un tribunal competente, independiente e imparcial, a obtener reparación, a no sufrir torturas ni malos tratos y a solicitar y a difundir información.

24 El estudio resalta la lectura que de este derecho ha realizado el Tribunal Europeo de Derechos Humanos a través de la inferencia del marco normativo a no sufrir torturas o malos tratos, el derecho a un recurso efectivo y el derecho a una investigación eficaz, a ser informado sobre los resultados, y, de cierta forma, del derecho a la vida; en el mismo sentido lo asume la Comisión Africana de Derechos Humanos y de los Pueblos que lo infiere del derecho a un recurso efectivo. Por su parte, la CIDH lo deriva del deber general de los Estados de respetar y garantizar los derechos humanos y los derechos a ser oído por un tribunal, competente, independiente e imparcial, a un recurso efectivo, a la protección judicial y a solicitar información. En todo caso, tanto el Comité de Derechos Humanos, el Tribunal Europeo de Derechos Humanos, la Comisión Interamericana de Derechos Humanos y la Comisión Africana de Derechos Humanos y de los Pueblo asocian al derecho con la tortura o maltrato. 
considerar la cuestión del derecho a la verdad, lo cual da cuenta del carácter transversal de este tema ${ }^{25}$; además, la Oficina del Alto Comisionado de las Naciones Unidas para los Derechos Humanos presentó un informe relacionado con el estudio sobre el Derecho a la Verdad (E/CN.4/2006/91 del 9 de enero de 2006) el cual se consolidó con la información enviada por varios Estados y las conclusiones del seminario de expertos sobre el derecho a la verdad organizado por la Oficina en octubre de 2005.

Posteriormente, el Consejo de Derechos Humanos solicitó a la Oficina la preparación de un informe de seguimiento al mismo, en el que se hiciera referencia a "las mejores prácticas nacionales e internacionales y en particular las medidas legislativas, administrativas o de otra índole, así como a los aspectos individuales y sociales de este derecho, teniendo en cuenta los puntos de vista de los Estados y de las organizaciones intergubernamentales y no gubernamentales competentes" ${ }^{26}$. El resultado de este mandato fue el informe $\mathrm{A} / \mathrm{HRC} / 5 / 7$ junio 7 de 2007, en el que se reafirma el derecho a la verdad reconocido en multiplicidad de tratados e instrumentos internacionales; se trata de una cuestión de alta complejidad, dado que se encuentra relacionado con varias obligaciones del Estado, como la de investigar y procesar a los responsables de las violaciones manifiestas de los derechos humanos y las infracciones graves del derecho humanitario, y de garantizar vías de recurso efectivas pues aquel se concretiza mediante las investigaciones judiciales; asimismo, se advierte que el contenido del derecho se encuentra vinculado además con el deber de memoria y el derecho a obtener una reparación en tanto que el esclarecimiento de los hechos contribuye tanto a ello como a la prevención.

Por otro lado, se hace una referencia a los mecanismos y medidas que favorecen el derecho a la verdad entre los que se destacan las comisiones de la verdad con vigencia durante el término de la transición inmediata, las comisiones de investigación que, como lo señala el Conjunto de Principios, corresponde a procesos no judiciales que complementan la función jurisdiccional en el esclarecimiento de los crímenes cometidos de manera masiva y sistemática así como la verificación de la verdad (Principio 5), y finalmente, los procedimientos judiciales nacionales o internacionales contra las personas que cometieron crímenes de guerra contra la población civil y en los que se debe garantizar la intervención de las víctimas en especial en los procesos de corte penal. El informe concluye que el mencionado derecho se encuentra en plena evolución, a raíz de las comunicaciones e información recibidas de Estados y organizaciones no gubernamentales, de modo que el balance da como positivo en el acogimiento por parte de los Estados que han promovido y aprobado disposiciones legales y jurisprudenciales a nivel nacional en relación con este tema así como la aprobación de instrumentos y pronunciamientos internacionales que abordan la cuestión de la verdad.

25 Naciones Unidas. Consejo de Derechos Humanos, Resolución E-CN_4.Res.2005-66, del 2005.

26 Naciones Unidas, Decisión 2/105. Derecho a la verdad. Consejo de Derechos Humanos. 
Finalmente, la Oficina del Alto Comisionado de Derechos Humanos presentó el informe A/HRC/12/19 del 21 de agosto de 2009, sobre actividades para asegurar el ejercicio del derecho a la verdad, en particular, respecto a las prácticas relacionadas con los archivos y los expedientes de violaciones manifiestas de los derechos humanos, así como los programas de protección de los testigos y otras personas que tomen parte en juicios por tales violaciones. En el documento se advierte acerca de la importancia del papel de los archivos y los archiveros en el apoyo de los derechos humanos en especial en los casos de desapariciones forzosas en donde las investigaciones pueden incluir la búsqueda de expedientes, entrevistas y actas de pruebas; además, el informe señala la relevancia que en materia de memoria y verdad tienen los expedientes de los órganos de justicia en la transición, los cuales, una vez completada la función de investigación y juzgamiento, cuentan con un valor permanente que debe ser transferido a los archivos del gobierno ${ }^{27}$.

El derecho a la verdad, en suma, como un tema transversal de amplia relevancia al abordar la protección, respeto y difusión de otros derechos humanos ha sido delineado a partir de un ámbito de aplicación circunscrito a las infracciones graves al DIH y violaciones manifiestas a los derechos humanos, como las ejecuciones extrajudiciales, la tortura y muy especialmente para desapariciones forzosas; sin embargo, su evolución y el desarrollo dentro del marco del Derecho Internacional de los Derechos Humanos ha extendido su contenido y está siendo emprendido cada vez con mayor fuerza y frecuencia en tratados e instrumentos internacionales, no solo como el derecho individual de la víctima o sus parientes de saber qué pasó, sino también el derecho colectivo de la sociedad de saber todo aquello acerca de lo ocurrido en el conflicto para evitar o prevenir la reproducciones futuras de dichas violaciones, conjuntamente, con el consecuente "deber de la memoria" a cargo del Estado para prevenir las distorsiones de la historia y asegurar a los pueblos la preservación de su historia como patrimonio ${ }^{28}$.

\section{ESCLARECIMIENTO DE LA VERDAD Y RECONOCIMIENTO DE RESPONSABILIDAD EN EL PROCEDIMIENTO TRANSICIONAL COLOMBIANO: EL CASO DE LA VERSIÓN LIBRE Y LA CONFESIÓN EN JUSTICIA Y PAZ}

La dinámica judicial de los procesos judiciales buscan, más que la verdad de lo acaecido, el convencimiento del juez o jurado por medio de elementos materiales de prueba que acrediten, más allá de toda duda, la responsabilidad del acusado, de

27 Oficina del Alto Comisionado para los Derechos Humanos, informe A/HRC/12/19 del 21 de agosto de 2009.

28 Ob. cit. Conjunto de principios para la protección y la promoción de los derechos humanos para la lucha contra la impunidad de Joinet. 
suerte que la "verdad judicial" solo es una consecuencia secundaria del proceso como mecanismo de solución de conflictos. Esa es la lógica que han seguido los métodos e instrumentos procesales en Colombia, los cuales de ordinario no han sido destinados a la construcción de una memoria o verdad histórica, sino que se encargan, en esencia, de establecer una verdad formal o procesal, como quiera que el fundamento de una condena se alcanza por medio de reglas precisas y aplicables a hechos penalmente relevantes.

La relación del Derecho penal y la verdad es estrecha en tanto que es en el proceso penal mediante el cual se pretende la armonización de intereses disímiles, como lo son la búsqueda de la verdad y la salvaguardia de los derechos individuales; por otra parte, diferente a lo que sucede con otra actividad judicial, la sentencia exige una motivación fundada en la comprobación de aspectos cognoscitivos de hecho y de Derecho, de modo que la legitimación y validez de las sentencias penales está en la comprobación de la "verdad" o, concretamente, una verdad procesal que se acerca, por lo menos de manera aproximada, a la realidad; una verdad que, además, no ha caído del cielo sino que es el producto de las pruebas y las refutaciones. También el discurso de la verdad procesal es fuente de legitimación externa (ético-político) del poder judicial, como quiera que la imposición de la pena en contra de un ciudadano se legitima no por la decisión de la mayoría, esto es, por una legitimación representativa o consensual como el caso del legislador, sino que en el caso de la labor judicial requiere de los discursos asertivos cuyo fundamento está en el esclarecimiento de la verdad y fiabilidad tanto fáctica como jurídica.

Tal relevancia se deriva, entre otras razones, en que el ejercicio del poder judicial y en especial el de carácter penal, toca sensiblemente las libertades de los ciudadanos: "En la jurisdicción penal, sin embargo, la verdad garantizada por la estricta legalidad es directamente un valor de libertad... porque el juicio de verdad es el único que no lesiona la dignidad del sujeto juzgado, gracias a su tendencial objetividad y refutabilidad... Conforme a este doble nexo entre razón y libertad, los valores de la jurisdicción penal se pueden identificar con la inmunidad de los ciudadanos frente al arbitrio y las intromisiones inquisitivas, con la defensa de los débiles mediante reglas de juego iguales para todos, con la dignidad de la persona del imputado y, en consecuencia, con el respeto también de su verdad"29.

Las prácticas judiciales que definen los sistemas de enjuiciamiento penal como acusatorio e inquisitivo toman la verdad como elemento fundante que se obtiene por medio del énfasis en la confianza o desconfianza del ejercicio del poder judicial y su relación con la verdad; de suerte que mientras en el método inquisitivo hay una confianza ilimitada en el ejercicio del poder y sus virtudes, así como su capacidad

29 Luigi Ferrajoli. Derecho y Razón. Teoría del Garantismo penal, Madrid, Editorial Trotta, 1995, p. 546. 
para el hallazgo de la verdad, en el método acusatorio desconfía del poder judicial como fuente autónoma de la misma, al punto que considera que la verdad no es obtenida por la práctica del poder en sí sino por las dinámicas de controversia entre las partes que se debaten entre el interés del culpable y la tutela del presunto inocente ${ }^{30}$.

Sin embargo, la formulación de un modelo de justicia con características restaurativas ha aportado al proceso penal el reconocimiento de ciertos derechos a la víctima más allá de la reparación económica de los daños sufridos y que cobije otros derechos fundamentales a su favor como el conocer la verdad; de manera sistemática la jurisprudencia de la Corte Constitucional ha abordado y profundizado acerca del contenido, alcance y desarrollo de los derechos de la víctima de un delito, a partir del análisis de la normatividad constitucional (arts. 1, 2, 15, 21, 93, 229, y 250 de la Carta Política), las disposiciones del Derecho Internacional Humanitario y los estándares del Derecho Internacional de los Derechos Humanos.

Desde el pronunciamiento en la Sentencia C-228 de 2002, se hace eco de la tendencia mundial de reconocer a la víctima o perjudicado el derecho a que a través del proceso penal se establezca la verdad sobre lo acaecido y se haga justicia ${ }^{31}$. En este sentido, el panorama del derecho a la verdad en escenarios judiciales toma relevancia cuando envuelve la investigación y juzgamiento de crímenes de connotación internacional dentro del contexto de la violencia de un conflicto armado, en donde la determinación de la responsabilidad de los individuos se mezcla con propósitos más elevados, como la consecución de la paz, la lucha contra la impunidad, la reconstrucción de identidades nacionales o la reconciliación nacional ${ }^{32}$.

Esta dinámica corresponde al proceso de Justicia y Paz que prevé la Ley 975 de 2005 , en el que se resalta el uso del escenario judicial penal no solo como instrumento en

30 Ibídem. Luigi FerRajioli L., p. 603.

31 Corte Constitucional. Sentencia C-228 de 2002. M. P.: Manuel José Cepeda Espinosa y Eduardo Montealegre Lynett: "De lo anterior surge que tanto en el derecho internacional, como en el derecho comparado y en nuestro ordenamiento constitucional, los derechos de las víctimas y perjudicados por un hecho punible gozan de una concepción amplia -no restringida exclusivamente a una reparación económica- fundada en los derechos que ellas tienen a ser tratadas con dignidad, a participar en las decisiones que las afecten y a obtener la tutela judicial efectiva del goce real de sus derechos, entre otros, y que exige a las autoridades que orienten sus acciones hacia el restablecimiento integral de sus derechos cuando han sido vulnerados por un hecho punible. Ello sólo es posible si a las víctimas y perjudicados por un delito se les garantizan, a lo menos, sus derechos a la verdad, a la justicia y a la reparación económica de los daños sufridos.

"De tal manera que la víctima y los perjudicados por un delito tienen intereses adicionales a la mera reparación pecuniaria. Algunos de sus intereses han sido protegidos por la Constitución de 1991 y se traducen en tres derechos relevantes para analizar la norma demandada en el presente proceso:

" 1 . El derecho a la verdad, esto es, la posibilidad de conocer lo que sucedió y en buscar una coincidencia entre la verdad procesal y la verdad real. Este derecho resulta particularmente importante frente a graves violaciones de los derechos humanos". 
la investigación, juzgamiento y sanción de los delitos comunes, de lesa humanidad o infracciones contra el DIH, sino que también con un componente fundamental referido al deber/derecho de verdad y memoria, con fundamento en el derecho inalienable, pleno y efectivo de la sociedad, y en especial las víctimas, "de conocer la verdad sobre los delitos cometidos por grupos armados organizados al margen de la ley, y sobre el paradero de las víctimas de secuestro y desaparición forzada. Las investigaciones y procesos judiciales a los que se aplique la presente ley deben promover la investigación de lo sucedido a las víctimas de esas conductas e informar a sus familiares lo pertinente" (Art. 7 Ley 975 de 2005).

De ello se desprende que el proceso de Justicia y Paz funge ya no como el simple mecanismo de solución de diferencias con miras a declarar la verdad judicial, sino que la dimensión de la verdad se edifica no solo por medio del derecho individual y colectivo que les corresponde a la víctima y a la sociedad, sino también a través de la obligación del Estado para que la misma sea garantizada de forma concreta y efectiva.

El "deber de memoria”, además, amplía su dimensión en este escenario pues la verdad es deber, y ante todo, presupuesto para quienes se acojan al procedimiento con la aspiración de obtener los beneficios previstos por esta legislación -desmovilizado - y causal de pérdida del beneficio de alternatividad ${ }^{33}$ si se desconoce o fragmenta. Así lo constató la Corte Constitucional en el estudio de exequibilidad de los artículos 17 y 25 de la ley 975 de 2005 y que posteriormente se estableció como criterio legal en el artículo $9^{\circ}$ del Decreto 3391 de $2006^{[34]}$. Y lo reitera la Corte Suprema de Justicia Sala de Casación Penal: "Ese derecho a la verdad trasladado al ámbito de la Ley de Justicia y Paz parte del supuesto de plenitud y veracidad en la versión que rinden los miembros del grupo armado organizado al margen de la ley, pues al someterse el desmovilizado a esta forma especial de justicia adquiere el compromiso de confesar de manera completa y veraz todos los hechos en los que ha participado o de los que tenga conocimiento, durante y con ocasión de su pertenencia al grupo armado ilegal..."35.

Para ello, la Ley 975 de 2005 dispone la construcción de la verdad desde la instancia inicial de la diligencia procesal de versión libre (17 de la L. 975 de 2005), que es presupuesto para la concesión de los beneficios y requisito de procedibilidad ${ }^{36}$, la cual rinde el desmovilizado, postulado por el Gobierno Nacional para acceder a los beneficios procesales, previa renuncia a su derecho constitucional de no autoincriminación y guardar silencio.

33 Artículo 3 de la Ley 975 de 2005.

34 Corte Constitucional, Sentencia C-370 de mayo 18 de 2006.

35 Corte Suprema de Justicia - Sala de Casación Penal. Radicado No. 30120, 23 julio de 2008.

36 Artículo 1 del Decreto 2898 del 29 de agosto de 2006. 
Desde este escenario, inicia la conciliación de la verdad expuesta y aportada por el procesado con el conocimiento particular de las víctimas y de la sociedad representada a través de instituciones como el Ministerio Público, que están legitimados para intervenir, controvertir y discutir el contenido de la versión del postulado. A la par, la Fiscalía ejerce un rol activo en consonancia con "el deber institucional de practicar cuanto medio probatorio esté a su alcance, con el fin de confirmar o infirmar lo confesado por el desmovilizado, resaltándose que en esa labor de verificación, es apenas natural y obvio que las víctimas jueguen un papel preponderante, pues, a su turno, pueden aportar elementos de juicio en uno u otro sentido" 37 .

El objetivo de esta etapa es el conocimiento judicial de todo lo acontecido durante el tiempo en que el desmovilizado estuvo vinculado al grupo armado ilegal y que tenga consecuencias jurídicas. Esta diligencia es medular en el desarrollo del proceso pues en la misma se inicia la constatación de la verdad de lo sucedido a partir de la información recolectada por la Fiscalía en las indagaciones preliminares así como con la manifestación del desmovilizado (es la única oportunidad que tiene el procesado para confesar) y la participación de las víctimas. En este escenario judicial, el desmovilizado-postulado, asistido por su defensor y ante el fiscal delegado, confiesa todos los hechos que, durante y con ocasión a su pertenencia al grupo armado ilegal, hubiera cometido o de los que tenga conocimiento, con la narración detallada de las condiciones de modo, tiempo y lugar de tales acontecimientos, los datos relacionados con su vinculación al grupo ilegal, los aspectos generales de creación, funcionamiento y operación de este, los modus operandi y en general de todas las circunstancias que favorezcan la efectiva obtención de la verdad.

Esta dinámica plurintermediaria tiene la importancia de ser el escenario de construcción de verdad y memoria pues de acuerdo con el modelo de Justicia y Paz la verdad histórica tiene una identidad con la declaración judicial de la verdad que ha sido constata y construida desde la versión libre, pues, como lo señaló la jurisprudencia, "historia que se revela, se sanciona y sobre la cual la sociedad debe hacer catarsis, es una historia que se declara judicialmente ante el juez colegiado" 38 .

La composición del deber que se le asigna al postulado de reconocer los hechos punible cometidos y narrar lo acontecido en el conflicto está circunscrita al instituto de la confesión, connatural a la versión libre, que en el escenario procesal de la Ley 975 de 2005 tiene una triple condición: como presupuesto de procedibilidad, la confesión es condición para el impulso procesal, de suerte que si la verdad de lo ocurrido resultara silenciada, total o parcialmente, falseada, deformada o tergiversada por parte del desmovilizado-postulado, este no podrá aspirar a la pena alternativa y por lo mismo a continuar en el proceso; en consecuencia, el incumplimiento por

37 Corte Suprema de Justicia, Sala de Casación Penal, Radicado 32022, 21 septiembre de 2009.

38 Corte Suprema de Justicia, Sala de Casación Penal, Radicado 29560, 28 mayo del 2008. 
parte del postulado de su compromiso de confesar habilita a la Fiscalía para pedir ante la Sala de Conocimiento su exclusión del proceso. Como medio de prueba debe tenerse en cuenta que la información proporcionada en la versión libre tiene plenos efectos probatorios por lo que en su recepción el fiscal debe asegurar que el acto de confesión cumpla cabalmente con los requisitos previstos en la ley -Decreto 2700 de 1991 y en la Ley 600 de 2000- para probar los hechos que se relatan ${ }^{39}$.

En cuanto al componente de verdad, señala la jurisprudencia, la confesión es una forma de reparación a las víctimas al preservar del olvido las infamias cometidas, reconstruir la historia e incentivar la conservación de la memoria colectiva; en estos términos, la confesión se identifica con el derecho a saber de las víctimas y la sociedad $^{40}$, vale decir, el conocer no solo las circunstancias de lo acontecido sino también las razones, sus partícipes y los métodos utilizados, entre otros aspectos; además, conforme a este componente, el desmovilizado-postulado tiene la responsabilidad de contribuir con su relato a la reconstrucción de la memoria colectiva, mientras que el fiscal, en un rol activo y no pasivo, debe interrogar al desmovilizado para el esclarecimiento de la verdad.

El componente de verdad visualiza la confesión no solo como el medio de prueba sustento de una sentencia condenatoria, sino que también la vincula a la consolidación y comprensión de los procesos históricos cuyo desconocimiento ha provocado un déficit democrático y participativo en el caso colombiano; la disponibilidad de estos instrumentos jurídicos aporta al empoderamiento para quienes de manera habitual habían sufrido la exclusión de sus pretensiones en la interpretación convencional de estos escenarios judiciales -víctimas-y con ello se progresa en la auto-reconstrucción del sistema en un sentido alternativo con ocasión del análisis, reformulación de hipótesis y elaboración de conceptos que puedan incidir en la transformación social ${ }^{41}$.

La confesión como un componente de verdad

... tiende a caracterizarse como una de las formas de reparación, destinada a preservar del olvido la memoria colectiva... El derecho colectivo a saber, busca que la sociedad en su conjunto conozca la verdad de lo ocurrido así como las razones y circunstancias en las que los crímenes se cometieron; además, se erige en una forma de reconstrucción de la historia, por cuanto muestra la manera como el sistema jurídico de una determinada sociedad in-

39 Corte Suprema de Justicia. Sala de Casación Penal. Ponente Augusto J. Ibáñez Guzmán. Radicado 31150. 12 d mayo de 2009

40 Ob. cit. Conjunto de principios para la protección y la promoción de los derechos humanos para la lucha contra la impunidad de Joinet Principio 2. El deber de la memoria.

41 Juan A. PÉrez Lledó. "Teorías críticas del Derecho. El uso alternativo del Derecho", en ERnESTo GARZÓn VALDEZ, y FrAnCisco J. LAPORTA. El derecho y la Justicia, España. 
tenta construir el futuro a través del rediseño del pasado y de su relación con éste. La reconstrucción de la memoria colectiva es una responsabilidad de quienes se postulan a la ley de justicia y paz, en virtud de su compromiso a confesar completa y verazmente los delitos cometidos al interior de los aparatos armados de poder renunciando, respecto de lo admitido, a la garantía procesal de la presunción de inocencia. Su tarea es insustituible, porque en su narrativa deberán visibilizar a las víctimas, reconstruir el pasado común, y proyectar la reconciliación en punto de lo irrepetible ${ }^{42}$.

De suerte que la confesión en este escenario, a diferencia de lo que ocurre en el proceso penal habitual, no es una opción sino que es parte indispensable de la versión libre y del proceso mismo, de modo que se trata de un acto-condición ${ }^{43}$. El relato del procesado en Justicia y Paz, entonces, se constituye en fuente fundamental del proceso de construcción de verdad histórica, y como tal al aludir a la confesión en este contexto, conjuntamente con su condición netamente inculpatoria, se redefine jurídicamente (es componente de verdad) y se le condiciona a que sea completa y $\operatorname{veraz}^{44}$.

\section{PRINCIPIO DE NO AUTO-INCRIMINACIÓN Y DERECHO A GUARDAR SILENCIO: FLEXIBILIZACIÓN EN JUSTICIA TRANSICIONAL.}

La confesión ha sido definida por esencia como el "... testimonio que presta el imputado de un hecho contrario a su interés..." 45 o como “... la declaración del acusado (en sentido genérico) donde narra o reconoce ser el autor o partícipe de unos hechos que la ley penal describe cono delito"46. Como lo señala Juan Marcone Alega: "En la exposición del acusado, la confesión es la manifestación que más se espera en el proceso penal. La confesión es la que atrae mayor interés, pero ni ésta se produce frecuentemente, ni tampoco es dable que cuando esto ocurre, que la confesión por si sola pueda inducir a pasar por alto otros importantes aspectos, dignos de ser tomados en consideración, bajo riesgo inminente de perder objetividad o llegar a conclusiones que se apartan de la verdad" 47 . Una de las grandes manifestaciones del derecho a la

42 Corte Suprema de Justicia, Sala de Casación Penal. Radicado n. . 31150, 12 de mayo de 2009.

43 Corte Suprema de Justicia, Sala de Casación Penal. Radicado n. ${ }^{\circ} 32022,21$ septiembre de 2009.

44 Artículo 9 del Decreto 3391 de 2006.

45 Alfonso Ortiz Rodríguez. Nuevo curso de derecho procesal penal, Medellín, Universidad de Medellín, 1983, p. 340. Citado en JAIRo PARRA QuiJano. Manual de Derecho Probatorio.

46 Ibídem.

47 Juan Marcone Moreno. Tratado de la Prueba Penal, Edit. Afa Editores, Lima, 1991, p. 263. Citado en Daniel ERnesto Peña. El instituto de la confesión sincera en el nuevo Código Procesal Penal peruano. 
presunción de inocencia es el derecho del ciudadano, en virtud de esa presunción, a no colaborar con su propia condena. La presunción de inocencia que supone el desplazamiento de la carga de la prueba hacia quien acusa, impide el hacer recaer en el acusado la obligación de declarar o aportar elementos de prueba que lo lleven a su propia incriminación.

A pesar de ello, el instituto de la confesión aun en este entorno no deja de ser una vertiente de las categorías jurídico-penales destinadas al estudio probatorio, pues aunque no se le limite a la búsqueda de la convicción acerca de la hipótesis defensiva o acusadora sí tiene una relación muy amplia con la credibilidad o la veracidad, esto es, con la idoneidad para demostrar los hechos relatados por lo que resulta “... imperioso observar tanto los preceptos procesales que la disciplinan, como la especialidad del instituto dentro del contexto de la justicia transicional, sin perder de vista las situaciones temporo-espaciales de los hechos que se pretenden reconstruir" 48 .

En este punto específico, surge la obligatoria remisión a los preceptos legales que gobiernan la confesión en los trámites previstos en el Decreto 2700 de 1991 y en la Ley 600 de 2000, en especial en lo que atañe con el análisis, primero, de la idoneidad demostrativa de la confesión, esto es, el mérito probatorio conforme a las reglas de la sana crítica, así como el examen de la pertinencia, eficacia, profundidad y todos los criterios para apreciar el testimonio ${ }^{49}$; y segundo, del juicio de legalidad formal ${ }^{50}$ que se refieren, entre otros aspectos a la voluntad, libertad, conocimiento y renuncia expresa del titular de su derecho a la presunción de inocencia (Art. 29 CP) y a la no autoincriminación (Art. 33 CP).

En un proceso evolutivo que relativiza la necesidad de obtener a cualquier costo -incluidos prácticas coercitivas, torturas y métodos crueles-, la confesión del procesado como prueba reina y, en consecuencia, el desarrollo jurídico penal, con base en la dignidad del ser humano como premisa mayor, sitúa al imputado como un sujeto de derechos que puede, legítimamente, oponerse a la atribución de responsabilidad por medio de la concreción de un derecho de defensa que incluya, según la máxima latina "Nemo tenetur se ipsum accusare", no solo la libertad de declaración, esto es, el derecho de ser oído por los tribunales, sino también la garantía de "callar" o "guardar silencio" 51 frente a la imputación, o por lo menos, de un resguardo que lo proteja de ser obligado a incriminarse.

\section{Ibídem.}

49 Corte Suprema de Justicia, Sala de Casación Penal. Radicado n. 31150.

50 Artículo 296 del Decreto 2700 del 91 y Artículo 280 de la Ley 600 de 2000: "Requisitos. La confesión deberá reunir los siguientes requisitos: 1. Que sea hecha ante funcionario judicial. 2. Que la persona esté asistida por defensor. 3. Que la persona haya sido informada del derecho a no declarar contra sí misma. 4. Que se haga en forma consciente y libre".

51 Barton L. Ingraham. "The Right of Silence, the Presumption of Innocence, the Burden of Proof, and a modest Proposal: a Reply to O’Reilly”, en The Journal of Criminal Law \& Criminology, Vol. 
En el ámbito nacional, la tradición jurídico penal ha situado la declaración del imputado con una triple condición: 1 . medio de vinculación al proceso, 2. medio de defensa para el procesado y 3 . medio de prueba; lo primero, en tanto que ante de la implementación de un proceso penal de corte acusatorio, en Colombia se encontraba vigente la "indagatoria" como acto procesal por medio del cual, aquel que era imputado de un hecho delictivo, adquiría la condición de sujeto procesal y quedaba formalmente incorporado al mismo, por lo tanto a partir del momento en el que era escuchado en indagatoria, el sujeto tenía plena claridad de que el Estado había iniciado en su contra una investigación y debería tomar, en consecuencia, una medida de carácter definitivo. Al respecto, expuso la Corte Suprema de Justicia, Sala de Casación Penal, "La comparecencia del imputado al proceso penal, al convertirse en uno de los ideales del Estado de derecho garantista que actúa sub leges -sometido a las leyes- y per leges -mediante leyes generales y abstractas- (...) Así pues, tanto la indagatoria como la declaratoria de persona ausente constituyen los medios de los cuales se vale el Estado jurisdicción para vincular al imputado al proceso penal..."

Su condición como medio de defensa se deriva de la facultad del acusado de explicar en su declaración la participación que tuvo o no en los hechos, su comportamiento, sus motivaciones o la respuesta personal a los cargos que se le formulan: "La diligencia de indagatoria, como medio de defensa y, a la vez, medio de prueba, forma parte del núcleo esencial del derecho fundamental al debido proceso que recoge el conjunto de garantías que protegen al ciudadano sometido a cualquier procedimiento y le aseguran, a lo largo del mismo, una recta y cumplida administración de justicia "53.

Y como medio de prueba, porque las explicaciones que son dadas por el procesado eran valoradas conjuntamente con los otros medios de prueba conforme a las reglas de la sana crítica; al respecto, ha referido la Corte Constitucional: "El derecho procesal moderno le reconoce a la indagatoria una doble connotación jurídica: como medio de defensa y como fuente de prueba de la investigación penal. Lo primero, porque a través de ella la ley le otorga al procesado el derecho a responder los cargos que se le hubiesen imputado previamente; lo segundo, porque de lo expresado en la diligencia puede el juez especializado encontrar o deducir indicios de responsabilidad en el delito que se investiga, y hallar razones que conduzcan a la inocencia o responsabilidad del acusado. En efecto, al constituirse la indagatoria en la primera oportunidad de defensa del sindicado dentro del proceso, resulta lógico deducir su calidad de pieza probatoria relevante para la investigación, pues las explicaciones que aquél pueda dar, permiten conocer información necesaria para llegar a la verdad material" 54 .

86, n. ${ }^{\circ} 2,1996$, Northwestern University; p. 564. Citado en Ignacio F. Tedesco. La libertad de la declaración del imputado: un análisis histórico-comparativo.

52 Corte Suprema de Justicia. Sala de Casación Penal, Radicado n. ${ }^{\circ}$ 11032, 25 de marzo de 1999.

53 Corte Constitucional, Sentencia C-403 28 de agosto de 1997.

54 Ibídem. 
Con la entrada en vigencia de un modelo de enjuiciamiento criminal de características acusatorias en Colombia, la versión del imputado o acusado se encuentran regidas por principios que lo reconocen como sujeto procesal dotado de derechos autónomos y en una posición de igualdad de armas frente al ente acusador como garantía del derecho de defensa:

El principio de igualdad de armas constituye un elemento esencial de la garantía del derecho de defensa, de contradicción, y más ampliamente del principio de juicio justo, y hace relación a un mandato según el cual, cada parte del proceso penal debe poder presentar su caso bajo unas condiciones y garantías judiciales, que permitan equilibrar los medios y posibilidades de actuación procesal, dentro de las cuales se presente como esencial las facultades en cuanto al material probatorio a recabar, de tal manera que no se genere una posición sustancialmente desventajosa de una de las partes frente a la otra parte procesal, como la que de hecho se presenta entre el ente acusador y el acusado, a favor del primero y [en] detrimento del segundo. El principio de igualdad de armas o igualdad de medios, supone entonces que la carga probatoria del acusador es proporcional a sus medios y que las reglas de ejercicio del principio contradictorio en virtud de esa carga, buscan equiparar la participación en el proceso penal, tanto optimizando lo más posible las garantías de la defensa, como incrementando la exigencia del cumplimiento de la labor probatoria del acusador. Para esta Corte el derecho de defensa en materia penal encuentra uno de sus más importantes y esenciales expresiones en el principio de igualdad de armas, en procura de garantizar la protección de los imputados frente a aquellas situaciones que desequilibran su actuación en el proceso ${ }^{55}$.

En ese sentido, la declaración del acusado dejó de ser un acto procesal de vinculación y por ende de ordinaria ocurrencia, puesto que la condición natural del proceso es la que el investigador "hable" con las huellas, manchas, evidencias, residuos, fluidos, testigos, rastros que deja la actividad criminal y, en general, con los elementos materiales de prueba que arroje la investigación criminal. El inculpado entonces guarda sus manifestaciones si así lo desea, para enfocar su defensa desde una perspectiva más técnica y científica.

La declaración del imputado está relacionada con el derecho a la no autoincriminación que deriva del respeto a la dignidad de la persona, ya que así se lo protege contra la posibilidad de ser forzado a revelar hechos incriminatorios que no le corresponden, evita el uso de la tortura o de otro medio para forzar confesiones, y establece que las aceptaciones de hechos y cargos obtenidas por estos métodos o cualquier otra forma de coerción son enteramente inaceptables. La prohibición de cualquier acto

55 Corte Constitucional, Sentencia C- 536 de 3008. 
que perturbe o vicie esa voluntad de declarar o de no hacerlo y las salvaguardias necesarias para cautelar esta libertad es lo que se conoce como la garantía y/o derecho de no auto-incriminación, y la finalidad de dicho principio es la de “... excluir la posibilidad de obligar al imputado de conocer activamente en la formación de la convicción sobre sí mismo y la forma de conseguirlo mediante le prohibición de utilizar en el proceso cualquier declaración del imputado que haya sido conseguida mediante la violación del principio del cual nos ocupamos" $"$.

La no autoincriminación, que constituye una de las garantías fundamentales del inculpado directa y estrechamente vinculada con la prohibición a la tortura, encuentra su origen en la oposición a aquellas prácticas inquisitoriales en procura de la obtención de la confesión como modo de expiar las culpas y "salvar el alma" 57 , en tanto que, durante esta etapa histórica, el acusado es considerado como un objeto en función del proceso desprovisto de cualquier opción de oponerse al señalamiento penal y, en consecuencia, como un medio para obtener la comprobación de la realidad judicial.

El advenimiento de un nuevo concepto del proceso penal con mayor nivel de garantías llevó a estudiar la necesidad de expulsar la tendencia de usar el cuerpo y el alma de los sospechosos en la obligación de probar, y con ello sin la vigencia de máximas como cofessio est regina probationum y confessus pro convicto habertu, la confesión ya no es el objetivo primordial del órgano judicial. Ahora, la lucha se centraba por un proceso penal con lineamientos garantistas y de corte acusatorio, público y contradictorio, entre otras características, en donde el acusado deja de ser el objeto del proceso para convertirse en sujeto del mismo, es decir, una parte del proceso cuya declaración es, además y ante todo, medio de defensa; en consecuencia, las declaraciones que el procesado haga en el proceso judicial deben estar precedidas de condiciones de libertad, tanto en lo referido a la de proporcionar o no la declaración como en el contenido de la misma. En efecto, como lo señala Ferrajioli ${ }^{58}$, el modelo garantista del proceso acusatorio se informa del principio de presunción de inocencia que, a su vez, direcciona la declaración del acusado hacia un medio de

56 Antonio PéRez Freyre. La garantía en el Estado Constitucional de Derecho, Madrid, Trotta, 1997, p. 30

57 Corte Constitucional, Sentencia C - 102 de 2005. “... En los procesos que realizaba el Tribunal -Tribunal de la Santa Inquisición-, como se recuerda, se consideraba que el mismo tenía por función investigar acusados, extraer la confesión y "salvar el alma”. De allí que la confesión fuera la prueba reina - probatio probatissima-, y para lograrla, los jueces debían procurar del encartado su confesión, utilizando cualquier medio: tormentos, amenazas, dádivas, todo con el fin de ahorrarle al funcionario la obligación de probar los cargos, pues con la confesión era suficiente. Aunado a las circunstancias de que se trataba de procesos oscuros y secretos, en los que los jueces no le informaban al acusado los motivos de la detención y, sin embargo, se les obligaba a contestar preguntas que no sólo los autoincriminaba, sino que podían constituir indicios para otras acusaciones distintas a las que originaron su detención e iniciar de esta forma otro proceso igualmente oscuro y secreto". 
defensa, un escenario en donde puede, legítimamente, refutar la acusación o introducir elementos para justificarse.

El derecho a no declarar en contra de sí mismo o a no confesarse culpable es una expresión del derecho de defensa, y en concreto, una modalidad de la autodefensa pasiva o, en otros términos, "la que se ejerce precisamente con la inactividad del sujeto sobre el que recae o puede recaer una imputación, quien, en consecuencia, puede optar por defenderse en el proceso en la forma que estima más conveniente para sus intereses sin que en ningún caso pueda ser forzado o inducido, bajo constricción o compulsión alguna a declarar contra sí mismo o a confesarse culpable"59. El derecho a guardar silencio y la garantía a la no autoincriminación han sido reconocidos en los estándares de las normas internacionales, primordialmente de derechos humanos y Derecho Penal Internacional, las cuales han desarrollado su protección como derecho fundamental dentro del marco de salvaguardia del derecho al debido proceso (por ejemplo, la Convención Americana de Derechos Humanos en su artículo $8^{\circ}$, el Estatuto de la Corte Penal Internacional, artículo 55; el Estatuto del Tribunal Penal Internacional para la Ex Yugoslavia, en su artículo 21 o el artículo 20 del Estatuto del Tribunal Penal Internacional de Ruanda).

En el derecho comparado, el desarrollo de esta garantía encuentra su fundamento en la figura del Duo Process of Law de la práctica judicial estadounidense. En concreto, las ejecutorias de la Suprema Corte de Justicia de Estados Unidos de América, establecieron, por medio de la llamada "Miranda Rule", el deber de informar al inculpado previamente un interrogatorio el derecho que tiene a guardar silencio, de que cualquier declaración que haga puede ser usada en su contra y de que tiene derecho a la presencia de un abogado.

Por su parte, el derecho "a guardar silencio" o la libertad a no declarar, como se ha visto en la evolución de la declaración de la declaración del imputado, era una garantía inconcebible cuando se consideró la confesión como Regina probationum la existencia del ius tacendi ${ }^{60}$; este derecho, instrumental del derecho a la defensa, se refiere en esencia al derecho a "no responder", o por lo menos a no ser obligado a hacerlo, por lo tanto su reconocimiento inicia desde el momento mismo en el que a un sujeto se le atribuye responsabilidad en un hecho punible, de modo que es posible su ejercicio desde que la policía, el ministerio público o el tribunal, realice un acto que signifique poner a una persona en la posición de tener que dar explicaciones sobre cualquier hecho inculpa. No es necesario, entonces, la privación de la libertad para el ejercer este derecho.

59 Sentencia del Tribunal Constitucional Español n..$^{\circ}$ 197/1995, f.j. 6 36/1983; 127/1992.

60 José María Tijerino Pachecho. “Acerca de la declaración del imputado", en Revista de ciencias penales, n. ${ }^{\circ} 18$, noviembre de 1990, pp. 21-30. 
La simple exhortación a decir la verdad, "así aparezca como un llamado y no una orden”, como lo advierte la Corte Constitucional, “... se convierte en una forma, sutil pero probablemente efectiva $-\mathrm{y}$ por ello inconstitucional-, de obtener en la diligencia de indagatoria la confesión del imputado. Más todavía, en cuanto se le advierte que debe decir únicamente la verdad, se excluye su silencio y se lo insta a expresar todo cuanto sabe o le consta, por lo cual dicho llamado, en boca de la autoridad que practica la diligencia y que está a cargo del proceso en su etapa previa, resulta ser una modalidad de incitación asimilable al juramento -que tiene el mismo propósito-y, por tanto, hace inoficiosa la exclusión del mismo, evitando toda estrategia de defensa y haciendo que los hechos relevantes, aun los que no favorecen al declarante, se lleven por éste al proceso de manera inmediata y exhaustiva, lo cual riñe abiertamente con la garantía contemplada en el artículo 29 de la Constitución sobre derecho de defensa" 61 .

Así las cosas, existe una tensión entre el deber de verdad y los derechos fundamentales como la defensa, "el derecho a guardar silencio" y "no autoincriminarse" forjados a través de la construcción del sistema penal garantista, en lo que toca con los mecanismos judiciales de transición y en especial con la legislación de Justicia y Paz, en la que también son relevantes las garantías del acusado y los límites de la persecución estatal, pues aunque los principios del proceso ordinario son aplicados con menos formalidad y más flexibilidad, ello no conlleva desconocer el hecho de que lo que centra la atención en la confesión y lo hace medular para las reglas y garantías procesales es que se trate de la manifestación de quien está siendo procesado. La calificación del desmovilizado-postulado en el proceso de Justicia y Paz no se basa en la etiqueta de "enemigo" ni que partir de ello, con base en una clave amigoenemigo, queda excluido de las libertades y derechos consagrados en la Constitución; esta distinción no corresponde al pensar del derecho en el sistema jurídico colombiano en el que no se alude, para la configuración a los fundamentos del orden, a un contenido político que considera altamente "las apariencias concretas de una situación considerada normal y de un tipo de persona considerado normal" 62 . Por el contrario, al desmovilizado-procesado le son reconocidos el respeto a la dignidad de la persona, la adecuada administración de la justicia, la eficacia en el juzgamiento de los hechos delictivos, la igualdad ante los tribunales, el derecho a ser oído públicamente y con las debidas garantías y la existencia de un procedimiento razonado con mecanismos de contrapeso a las atribuciones del Estado, los cuales se enmarcan dentro de los principios básicos de un Estado Social de Derecho.

61 Ob. cit. Sentencia C-621 de 1998.

62 Carl Schmitt. "Distinción de los modos de pensar la ciencia jurídica" en Sobre los tres modos de pensar la ciencia jurídica, Madrid, Tecnos, 1996, pp. 9 y 25. 


\section{CONCLUSIÓN}

En los eventos prácticos de Justicia y Paz, la construcción de la verdad y la memoria colectiva a través de la declaración judicial enfrentan la satisfacción de la Justicia y la verdad respecto de graves violaciones de los derechos humanos y el DIH y el derecho de no autoincriminación y el derecho a guardar silencio. En ese evento, la tensión entre los dos preceptos debe ser resuelto no por el modelo interpretativo según el cual el órgano facultado para aplicar las reglas normativas infiere del universo jurídico los valores que considera aplicables al caso y escoja entre una de ellas ${ }^{63}$, pues en este caso, es posible que el derecho del procesado sea el desechado.

El interrogante corresponde entonces a cuál debe ser el contenido de la confesión, la garantía fundamental de no autoincriminación y el derecho a guardar silencio en el proceso previsto por la Ley 975 de 2005 (Justicia y Paz), teniendo en cuenta que dicha ley se caracteriza por admitir la aplicación de una forma especial de administración de justicia en favor de la consecución de la paz pero sin inhabilitar la obligación del Estado de investigar, enjuiciar y sancionar las graves violaciones a los derechos humanos y al $\mathrm{DIH}^{64}$; a partir de ese escenario, la implementación del proceso de Justicia y Paz impone el cumplimiento de una serie de estándares en pro del reconocimiento de los derechos de las víctimas -y de la sociedad en general-a la verdad, la justicia y la reparación, y exige la construcción de la memoria histórica desde la identificación y aceptación de la verdad de los delitos cometidos por parte de sus perpetradores.

El modelo sistémico anula las tensiones señaladas por medio del consenso acerca de la efectivización de los derecho a la verdad, justicia, reparación y la construcción de memoria a partir de la renuncia de los derechos fundamentales del postuladodesmovilizado, a partir del reforzamiento en las condiciones del conocimiento e información precisa que tenga el procesado acerca de la magnitud y de las exigencias jurídicas y sociales, esto es, la condición de la exhortación como salvedad a la no autoincriminación es más exigente pues no solo se circunscribe a que la voluntariedad y la libertad en la declaración no sea eliminada ni coartada "por ningún acto o situación de coacción física o moral, por la promesa ilegítima de una ventaja o por el engaño", sino que corresponde además al conocimiento claro y específico de que su autoincriminación es fuente de construcción de memoria histórica, deber del postulado y presupuesto de los beneficios.

63 Hans Kelsen. "El fundamento de validez de un orden normativo: la norma fundante básica", en Teoría Pura del Derecho, México, Porrúa, 1997 (1960), p. 215.

64 Conforme a lo previsto en el artículo 1 de la Ley 975 de 2005, "La presente ley tiene por objeto facilitar los procesos de paz y la reincorporación individual o colectiva a la vida civil de miembros de grupos armados al margen de la ley, garantizando los derechos de las víctimas a la verdad, la justicia y la reparación". 


\section{BIBLIOGRAFÍA}

Andreu-Guzmán, Federico. Derecho a la Verdad y Derecho Internacional. Subdirección de Litigio y Protección Jurídica de la Comisión Colombiana de Juristas, Bogotá, Comisión Colombiana de Juristas, primera edición, 2012.

Bugnion, FrançoIs. Le Comité international de la Croix-Rouge et la protection des victimes de la guerre. Ginebra: Ed. Comité International de la Croix-Rouge, 1994.

COMisión InTERAmericana De Derechos Humanos (1998). Informe No 25/98 Casos $11.505,11.532,11.541,11.546,11.549,11.569,11.572,11.573,11.583,11.585$, $11.595,11.652,11.657,11.675$ y 11.705 . Chile. 7 de abril de 1998 .

Corte Constitucional. Sentencias C- 536 de 2008, C-403 28 de 1997, C - 102 de 2005, C-228 de 2002. M

Corte Interamericana de Derechos Humanos. Caso Bámaca Velásquez vs Guatemala. Fondo. Sentencia de 25 de noviembre de 2000. Serie C No. 70; Caso Cantoral Benavides, Reparaciones, supra nota 5, párr. 69; Caso Villagrán Morales y otros, Reparaciones, supra nota 5, párr. 100; y Caso Paniagua Morales y otros, Reparaciones, supra nota 5, párr. 200. Caso Castillo Páez, Sentencia de 3 de noviembre de 1997. Serie C No. 34, párr. 90; Caso Caballero Delgado y Santana. Reparaciones (art. 63.1 Convención Americana sobre Derechos Humanos). Sentencia de 29 de enero de 1997. Serie C No. 31, párr. 58; y Caso Neira Alegría y Otros, Reparaciones, supra nota 38, párr. 69. Caso Castillo Páez, supra nota 6, párr. 90. Caso Barrios Altos vs. Perú. Fondo. Sentencia de 14 de marzo de 2001. Serie C n. ${ }^{\circ}$ 75. Caso de la Masacre de La Rochela vs Colombia. Fondo, Reparaciones y Costas. Sentencia de 11 de de mayo de 2007. Serie C n. ${ }^{\circ}$ 163. Caso Bámaca Velásquez vs Guatemala.

Corte Suprema de Justicia - Sala de Casación Penal. Radicados No. 30120, 23 julio de 2008. No. 32022, 21 septiembre de 2009. No. 29560, 28 mayo del 2008, 31150,12 de mayo de 2009.

FerRajoli Luigi. Derecho y Razón. Teoría del Garantismo penal, Madrid, Editorial Trotta, 1995.

Henckaerts, Jean-Marie y Doswald-Beck, Louise. El Derecho internacional humanitario consuetudinario, Volumen I, Normas, Ediciones Comité Internacional de la Cruz Roja, s.f.

IngRAHAm, BARTON L. "The Right of Silence, the Presumption of Innocence, the Burden of Proof, and a modest Proposal: a Reply to O'Reilly", en The Journal of Criminal Law \& Criminology, Vol. 86, n. ${ }^{\circ}$ 2, Northwestern University, 1996. 
KeLSEn, HAns. "El fundamento de validez de un orden normativo: la norma fundante básica”, en Teoría Pura del Derecho, México, Porrúa, 1997 [1960].

Marcone Moreno, Juan. Tratado de la Prueba Penal, Lima, Edit. AFa Editores, 1991.

NACIONES Unidas. The rule of law and transitional justice in conflict and postconflict societies, $\mathrm{S} / 2004 / 16$.

NACIONES UnIDAS. Informe del Secretario General sobre el estado de derecho y la justicia de transición en las sociedades que sufren o han sufrido conflictos, S/2004/616. Párr. 50.

NACIONES Unidas. The rule of law and transitional justice in conflict and postconflict societies, S/2004/16

NAQVi, YASMin. "El derecho a la Verdad en el Derecho Internacional: ¿realidad o ficción?", en International Review of the Red Cross, junio de 2006, n. ${ }^{\circ} 862$ de la versión original.

Ortiz Rodríguez, Alfonso. Nuevo curso de Derecho procesal penal. Medellín: Universidad de Medellín, 1983.

Parra QuiJano, Jairo. Manual de Derecho Probatorio, s.f.

Peña, Daniel ERnesto. El instituto de la confesión sincera en el nuevo Código Procesal Penal peruano, s.f. 